\title{
Amount of information and polarity of attraction
}

\author{
MARTIN F. KAPLAN \\ Northern Illinois University, DeKalb, Illinois 60115
}

\begin{abstract}
In two experiments, subjects given larger sets of information judged others more extremely than did subjects given smaller sets. This set-size effect emerged only when subjects were made aware of relative numerosity of stimuli. The condition of awareness helps reconcile previous disparities between studies in which subjects judge one-size vs. multiple-sized sets. It is suggested that increased confidence underlies the polarizing effect of larger set size and that confidence requires knowledge that one could have received less information. This knowledge is often lacking when subjects are given only one set size.
\end{abstract}

Given different amounts of isovalent information about others, even with average likableness value held constant, we generally form more polar impressions of likableness with larger information sets. That is, six positive characteristics will lead to more liking than will three equally positive characteristics, and conversely, six negative characteristics will produce more disliking than will three. This set-size effect is well documented in person perception research (e.g., Anderson, 1974). The findings are not unanimous, though: Set-size effects are robust when subjects judge several different-sized sets, but they are absent when each subject judges only one set size (Byrne \& Nelson, 1965; Podell \& Amster, 1966).

Set-size effects are critical for conceptual treatments of attraction. Anderson's integration model (Kaplan \& Anderson, 1973) characterizes attraction as an averaged function of stimulus information, weighted by amount of information, and of a more neutral initial impression; the model therefore predicts a set-size effect. Byrne's proportionality model (Byrne \& Nelson, 1965) proposes attraction as a function of the proportion of positive information of the total, predicting no set-size effect (see Kaplan \& Anderson, 1973, for a comparative analysis).

One important difference between designs in which set size is varied within or between subjects is that subjects in the latter do not know that they could have received more (or less) information; that is, set size is not salient. Since the experimental task is unique for subjects, they have no way of knowing whether they have a lot (or little) information to evaluate; therefore, they are less likely to give extreme responses. If one creates, in a between-subjects design, the psychological conditions of salience fostered in a within-subjects design, contradictory findings can be reconciled, and set-size salience can be demonstrated as a requisite for polarization. The experiments reported here explore this possibility.

In addition to salience differences due to experimental design, another source of contradictory findings may be use of different stimuli. Byrne (1971) uses attitude stimuli, whereas Anderson (1974) uses trait stimuli. The first experiment here uses attitude stimuli, and the second, trait stimuli, in an effort to show functional equivalence.

\section{METHOD}

\section{Experiment 1}

Attitude stimuli. Six attitude topics were selected to respresent a broad range of interest and importance for students. For each topic, three "pro" and three "con" statements were obtained from relevant attitude scales (Shaw \& Wright, 1967). Audiotapes were constructed in which a confederate read an assertion for the topic (e.g., "There should be one national presidential primary instead of the present system of several statewide primaries"), then reported his agreement or disagreement, and, finally, gave three statements supporting his attitude. For each assertion, one tape track contained agreements and the other contained disagreements.

Procedure. Subjects were told that the experiment was concerned with methods of opinion polling. They were to be polled by another subject on six opinion topics. After each topic was read to them by the pollster in the next room, they were to agree or disagree with the statement, giving a brief reason for their response. Following each response, the pollster was to give his own response in the same manner. The alleged purpose of this was to see how successful opinion polling would be if untrained pollsters reported their own attitudes to interviewees. Half of the subjects were told that the pollster was instructed to respond to all six items (Set Size 6); the remainder were told he could respond to only three of the six (Set Size 3). The three responses heard in the Set Size 3 condition were randomly selected for each subject, and the subject was informed of this. All subjects gave their attitudes to all six items.

The second independent variable was salience of the size of the single attitude set given to each subject. For half the subjects, salience was enhanced by telling the subjects that some subjects would be privy to only three of the pollster's attitudes (if subjects were in the condition receiving six pollster attitudes) or that some subjects would hear all six of the pollster's attitudes (if subjects heard three attitudes). Thus, subjects in the Set Size 6 condition were made aware that Set Size 3 was possible, and vice versa for those in the Set Size 3 condition. The remaining subjects were told nothing of the possibility of other subjects' receiving more (or less) information. This required that subjects in the Set Size 3 condition be polled on only three topics. 
Pollster's responses were selected to be in agreement or disagreement with the subject on two-thirds of the items. Half the subjects in each set size by salience cell encountered agreement, and half received disagreement. Thus, there were eight treatment cells based on set size, salience of set size, and proportion of agreement. Forty-eight introductory psychology students served as volunteer subjects for extra course credit. Three students of each sex were assigned to each cell.

A posttreatment questionnaire embedded two dependent measures among items related to poll taking. The first consisted of two items from Byrne's (1971) Interpersonal Judgment Scale (JS) relating to liking for the pollster and desirability as a work partner. Subjects select an alternative for each, indicating the extent of liking and desirability, and the responses are summed to yield an attraction score ranging from 2 to 14 . The second dependent measure was a $120-\mathrm{mm}$ line, with endpoints labeled "Dislike very much" and "Like very much," on which subjects marked the point representing their feelings about the pollster on a $100-\mathrm{mm}$ line, with endpoints of "extremely unconfident" and "extremely confident." When questioned during the postexperimental interview, no subjects expressed awareness of the purpose of the salience manipulation. In response to detailed questioning about the polling procedure, all seemed convinced that the polling was genuine and that the confederate was real.

\section{Experiment 2}

Experiment 1 increased subjects' awareness that their six attitude stimuli constituted a "large" set of information or that their three stimuli were few. In Experiment 2, expectations regarding the "largeness" of sets of three and six stimuli were orthogonally varied with set size. Again, each subject received only one set size.

Stimuli. Stimulus persons were described by sets of three or six adjective traits, four sets of each (see Kaplan, 1972, Experiment 2, for construction details). Traits within each set were selected to maximize intraset homogeneity of normative likableness value and to minimize mutual denotative redundancy. Within each set size, two sets contained highly likable traits $(\mathrm{H})$ and two sets were of highly dislikable traits (L). Moreover, sets were equated across sizes for mean normative likableness value; on a 7-point scale $(0-6)$, these values were: $5.29(6 \mathrm{H}), 5.26(3 \mathrm{H})$, $.76(6 \mathrm{~L})$, and $.76(3 \mathrm{~L})$.

Each subject judged all four sets of one size, that is, two replications each of $\mathrm{H}$ and $\mathrm{L}$ sets. Within each of two treatment conditions (see below), presentation order was counterbalanced so that a given subject judged stimulus sets in one of four sequences: $\mathrm{H}^{1} \mathrm{~L}^{1} \mathrm{H}^{2} \mathrm{~L}^{2}, \mathrm{H}^{2} \mathrm{~L}^{2} \mathrm{H}^{1} \mathrm{~L}^{1}$, or $\mathrm{L}^{2} \mathrm{H}^{2} \mathrm{~L}^{1} \mathrm{H}^{1}$, where superscripts 1 and 2 designate stimulus set replications.

Procedure. Experimental booklets contained four person descriptions, one to a page. Instructions asked for feelings about several people, each described by one or more one-word descriptions supplied by reliable acquaintances. Feelings were expressed by marking an unsegmented $120-\mathrm{mm}$ line with endpoints labeled "Dislike very much" and "Like very much." To anchor judgments, subjects were told to think of a person they knew whom they liked extremely well and to rate this person on the extreme right of the line and then to think of a personally known extremely dislikable person and mark the extreme left of the line.

Each subject was subjected to one of two treatment conditions. Subjects in the first condition were led to believe they could have received less information than they actually received, but due to chance factors in a random assignment scheme, they were receiving more information than most other subjects. Conversely, in the second condition, subjects were led to believe they were receiving less information than most others. Subjects receiving sets of six traits in the more-than-others condition were told that up to six traits were obtained for some of the stimulus persons (from six different sources) but, due to time pressures, only three were available for most stimulus persons. Similarly, subjects receiving three traits were told that up to three descriptions were initially elicited but only one trait was obtainable for most stimulus persons. On the other hand, subjects receiving 6 traits in the less-than-others conditions were instructed that from 6 to 12 traits were obtained for each set, depending on time pressures, with most sets in the upper ranges. Available traits for subjects receiving three traits in this condition ranged from three to six. Further description of experimental requirements and limitations made particularly salient the subject's wealth or deficiency in information. That all four sets were of the same size was attributed to a need for experimental uniformity.

In summary, all subjects received two $\mathrm{H}$ and two $\mathrm{L}$ sets in one of four balanced sequences. The two between-subjects conditions were set size (three or six) and instructions regarding the relative numerosity of information (more than or less than others). Eighty introductory psychology students volunteered for extra course credit. Twenty subjects, 10 of each sex, served in each treatment by set size condition.

\section{RESULTS}

\section{Experiment 1}

Mean confidence ratings, in millimeters, are given in Table 1A. Data are collapsed across stimulus proportions, since predictions were for set size within salience condition. Predictions were confirmed. Only in the salient instructions condition did larger set size lead to greater confidence. When the subjects had no means of knowing whether their stimulus set could be considered "large" or "small," confidence was at the same level as the smaller set size in the salient condition. One possible implication is that six items of attitude stimuli do not in themselves inspire much confidence in judging another person. It is only when the subjects realize that judgment might be based on but three items that six items assume greater importance.

An analysis of variance of the complete design yielded the expected interaction between set size and salience instructions $[F(1,40)=4.76, p<.05]$. In addition, effects for attitudes and salience instructions were significant $[\mathrm{Fs}(1,40)=4.37,6.10$, respectively; ps $<.05]$, and the set-size effect was marginally significant $[F(1,40)=3.23, p<.10]$. The attitudes effect was not unexpected; it reflects greater confidence for negative stimuli compared with positive $($ means $=50.21$

\section{Table 1}

(A) Confidence as a Function of Set Size of Attitudes and Salience of Set Size and (B) Attraction as a Function of Set Size, Proportion of Agreeing Attitudes, and Salience of Set Size

\begin{tabular}{|c|c|c|c|c|c|c|}
\hline \multirow{3}{*}{$\begin{array}{r}\text { Set } \\
\text { Size }\end{array}$} & & & \multicolumn{4}{|c|}{ (B) Attraction } \\
\hline & \multicolumn{2}{|c|}{ (A) Confidence } & \multicolumn{2}{|c|}{$\mathrm{S}$} & \multicolumn{2}{|c|}{$\mathrm{C}$} \\
\hline & $\mathbf{S}$ & $\mathrm{C}$ & $.33^{*}$ & $.67 *$ & $.33^{*}$ & $.67 *$ \\
\hline 3 & 42.67 & 40.00 & 9.33 & 10.83 & 6.67 & 11.00 \\
\hline 6 & 60.83 & 38.55 & 8.33 & 11.83 & 9.50 & 11.16 \\
\hline
\end{tabular}

Note-S = set-size-salient instructions; $C=$ control instructions. *Proportion of agreeing attitudes. 
Table 2

Attraction Polarity as a Function of Set Size of Traits Judged Relative to Others

\begin{tabular}{|c|c|c|}
\hline \multirow[b]{2}{*}{ Set Size } & \multicolumn{2}{|c|}{ Relative to Others } \\
\hline & More Than Others & Less Than Others \\
\hline $\begin{array}{l}3 \\
6\end{array}$ & $\begin{array}{l}45.24 \\
48.70\end{array}$ & $\begin{array}{l}41.98 \\
44.25\end{array}$ \\
\hline
\end{tabular}

Note-Scores indicate millimeters removed from scale midpoint. Higher scores reflect greater polarity.

and 40.67, respectively). Many studies have reported that negative stimuli carry greater weight than do positive stimuli (see, e.g., Hodges, 1974).

To the extent that confidence judgments are related to weighting, the Salience by Set Size interaction noted for confidence judgments should replicate for liking judgments. Mean attraction responses on the IJS, given in Table 1B, confirmed this prediction. Increased set size led to greater extremity effects for the salient condition, but not for the control condition. The statistical test of this prediction lies in the interaction among set size, attitudes, and salience instructions, which was significant $[F(1,40)=4.00, p<.06]$. The only other effect to reach significance was that for attitudes $[F(1,40)=4.25, p<.05]$. Similar results obtained for the rated likableness ratings; the interaction among set size, attitudes, and salience instructions was significant $(\mathrm{F}=5.60)$, and greater agreement led to greater ratings of likableness $(\mathrm{F}=5.29)$.

Thus, subjects must be aware of potential variations in the amount of information they might receive in order for set size to affect stimulus weighting in judgment. And awareness of potential variations is also required to obtain a set-size effect on attraction response extremity.

\section{Experiment 2}

Likableness ratings (on a 120 -mm line) were pooled across stimulus replications and presentation sequences for each set size (three or six) by instruction treatment (received more than others or less than others) combination. Ratings were converted to polarity scores by measuring the absolute distance between a rating and the scale midpoint. Since analyses of polarity scores showed neither main effects nor interactions for trait likableness value, data in Table 2 are averaged over trait sets.

Several aspects of the data are worth noting. First, a numerical set-size effect was obtained; responses to six traits were more polar than were those to three traits $[F(1,76)=8.13, p<.01]$. And, independent of numerical set size, responses were more polar to sets specified as larger than to sets identified as smaller $[F(1,76)=11.24, p<.01]$. Finally, the effect of numerical set size was greatest when six traits were characterized as "a lot" and three traits as "few," but it disappeared completely when six traits were "few" and three traits were "a lot." And so, subjects" beliefs about the relative adequacy of provided information can modify the polarizing effect of numerical set size.

No other effects reached statistical significance.

\section{DISCUSSION}

The experiments show that set-size polarity affects are obtainable, even with the paradigm and stimuli typically employed in attitude-attraction research. Moreover, measures regarding another's attractiveness and likableness rating scales give the same pattern of results. Paradigmatic differences, such as those stemming from judgments of single vs. multiple set sizes, are important only to the extent that design obscures the relativity of amounts of information. When the relative amount of information is salient, increasing the amount of isovalent information will polarize the response. These findings argue against a model of attraction formation based solely on proportion of positive stimuli (Byrne, 1971), since the model cannot account for extremity effects resulting from increased amount and/or importance of constant-proportion information (see Kaplan \& Anderson, 1973, for a detailed analysis of this problem). Moreover, the failure of a proportionality rule, along with the finding of parallel set-size effects in person perception an attraction paradigms, nullifies the Byrne, Clore, Griffitt, Lamberth, and Mitchell (1973) argument that person perception and attraction involve distinct processes.

On the contrary, a weighted averaging model of the judgment process, with an allowance for an initial impression less polar than information, provides for polarization effects in a variety of paradigms. Polarization follows from an increase in weight of the information relative to the initial impression. For information weight to be affected by stimulus or situational variables, these variables must be salient to the subject. And so, increased amounts of information will not increase information weight unless the subject is aware that he or she has been given a more sizable amount. Awareness of set-size relativity, then, accounts for the relatively small number of previous failures to replicate polarization effects, and these findings reconcile previously contradictory results.

There remains the argument that in "real life" we often form judgments of others one person at a time. But the amount of information about any one person may be made salient by the varying amounts obtained in previous social encounters, which act as "practice sets," or comparison set sizes.

These data implicate subjective confidence as crucial to the mechanism by which increased numerosity of stimuli polarizes judgment. Correlative evidence shows that confidence increases with set size (Posavac \& Pasko, 1971), as does judgment of "truth" of information (Gollob, Rossman, \& Abelson, 1973). While increased confidence may be due to extremity of the response to the person when set size is increased (Lee \& Ostrom, 1976), this study shows that subjects must be aware of the relative numerosity of stimuli before they can venture an extreme response.

Finally, it should be noted that the demonstrated role of knowing whether one has received more or less information does not preclude other contributors to set-size effects, such as reference scale shifts (Sloan \& Ostrom, 1974).

\section{REFERENCES}

Anderson, N. H. Information integration theory: A brief survey. In D. H. Krantz, R. C. Atkinson, R. D. Luce, \& P. Suppes (Eds.), Contemporary developments in mathematical psychology (Vol. 2). San Francisco: Freeman, 1974.

Byrne, D. The attraction paradigm. New York: Academic Press, 1971.

Byrne, D., Clore, G. L., Griffitt, W., Lamberth, J., \& 
Mitcheld, H. E. When research paradigms converge: Confrontation or integration? Journal of Personality and Social Psychology, 1973, 28, 313-320.

Byrne, D., \& Nelson, D. Attraction as a linear function of proportion of positive reinforcements. Journal of Personality and Social Psychology, 1965, 1, 659-663.

Gollob, H. F., Rossman, B. B., \& Abelson, R. P. Social inference as a function of the number of instances and consistency of information presented. Journal of Personality and Social Psychology, 1973, 27, 19-23.

Hodges, B. H. Effect of valence on relative weighting in impression formation. Journal of Personality and Social Psychology, 1974, 30, 378-381.

Kaplan, M. F. The modifying effect of stimulus information on the consistency of individual differences in impression formation. Journal of Experimental Research in Personality, 1972, 6, 213-219.

Kaplan, M. F., \& ANderson, N. H. Information integration theory and reinforcement theory as approaches to interpersonal attraction. Journal of Personality and Social Psychology, 1973, 28, 301-312.

LeE, A. G., \& Ostrom, T. M. Set size and impression certainty: Cue vs. extremity explanations. Bulletin of the Psychonomic Society, 1976, 8, 371-373.

Podell, J. E., \& Amster, H. Evaluative concept of a person as a function of the number of stimulus traits. Journal of Personality and Social Psychology, 1966, 4, 333-336.

Posavac, E. J., \& Pasko, S. J. Interpersonal attraction and confidence of attraction ratings as a function of number of attitudes and attitude similarity. Psychonomic Science, 1971, 23, 433-435.

Shaw, M. E., \& Wright, J. M. Scales for the measurement of attitudes. New York: McGraw-Hill, 1967.

Sloan, L. R., \& Ostrom, T. M. Amount of information and interpersonal judgment. Journal of Personality and Social Psychology, 1974, 29, $23-29$.

(Received for publication June 9, 1981.) 